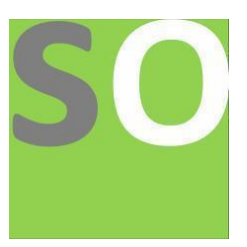

Article title: Identification of CYP2D6 allelic mutations in a sub-set of Karachi population

Authors: Tamkeen Fatima[1]

Affiliations: Dr. Panjwani Center for Molecular Medicine and Drug Research[1]

Orcid ids: 0000-0001-7728-4011[1]

Contact e-mail: tamkeenfatima@hotmail.com

License information: This work has been published open access under Creative Commons Attribution License http://creativecommons.org/licenses/by/4.0/, which permits unrestricted use, distribution, and reproduction in any medium, provided the original work is properly cited. Conditions, terms of use and publishing policy can be found at https://www.scienceopen.com/.

Preprint statement: This article is a preprint and has not been peer-reviewed, under consideration and submitted to ScienceOpen Preprints for open peer review.

DOI: 10.14293/S2199-1006.1.SOR-.PPV2GGJ.v1

Preprint first posted online: 25 March 2021

Keywords: CYP2D6 alleles; Polymorphism; Depression; Drug metabolism; Karachi population. 


\title{
Identification of CYP2D6 allelic mutations in a sub-set of Karachi population
}

\author{
Tamkeen. Fatima ${ }^{1 *}$, Asmat. Salim ${ }^{1}$, Farah. Zeb², Ahsana. Dar. Farooq ${ }^{2,3}$ \\ ${ }^{I}$ Dr. Panjwani Center for Molecular Medicine and Drug Research, International Center for
} Chemical and Biological Sciences, University of Karachi, Karachi, Pakistan

${ }^{2}$ Pharmacology Section, H.E.J. Research Institute of Chemistry, International Center for Chemical and Biological Sciences, University of Karachi, Karachi, Pakistan

${ }^{3}$ Pharmacology Section, Hamdard Al-Majeed College of Eastern Medicine, Hamdard University Karachi, Pakistan, *Corresponding author at: Dr. Tamkeen Fatima, email: tamkeenfatima@hotmail.com 突梁92- (021) 111222 292; Fax: + $922134819018-9$

CYP2D6 gene polymorphism is considered a main obstacle in the process of drug metabolism under clinical diseases that affect pharmacokinetics of $\sim 25 \%$ of antidepressants and other drugs. Inter-individual variation occurs in the amount and functional activity of CYP2D6 enzyme produce undesirable side effects. The primary aim of current research is to evaluate gene and genotypic frequencies of CYP2D6 $* 1$ extensive metabolizer, $* 4$ poor metabolizer and $* 10$ intermediate metabolizer allelic variants among depressed patients and compared with normal subjects and other populations. Human genomic DNA was isolated. Genotyping was performed by Polymerase chain reaction followed by restriction endonucleases digestion for variants analysis. The results indicated gene frequency of CYP2D6*1 was 59\% (CI 49.6,68.3\%) in normal subjects whereas, CYP2D6*4 was 13\% (CI 3.7, 22.3\%) and CYP2D6*10 was 54\% (44.7, $63.3 \%$ ) predominantly found in depressed patients. The results demonstrate pronounced association of CYP2D $6 * 4$ and $* 10$ allelic variants with patient's drug response activity.

Key words: CYP2D6 alleles; Polymorphism; Depression; Drug metabolism; Karachi population. 


\begin{abstract}
Abbreviations
Extensive metabolizer, EM; poor metabolizer, PM; intermediate metabolizer, Polymerase chain reaction, PCR ; IM; intermediate metabolizer; Bacillus stereothermophilus, Bst N1; Hemophilus parahemolyticus, Hph1; World health organization, WHO; Hamilton Depression Rating scale, HAM-D Key; Clinical Pharmacogenetics Implementation Consortium, (CPIC).
\end{abstract}

\title{
Introduction
}

Depressive disorder is a worldwide problem which affects 264 million people and ranked in fourth position among the global burden of diseases. In 2010 study, depressive disorders was reported the second leading cause of mental disability in Canada, the United States and globally $[1,2]$. According to world health organization (WHO) about 340 million people above the age of 18 suffer from depressive disorders and 800, 000 people die due to suicide every year. From 2013 to $2016,10.4 \%$ of women were found to have depression as compared to men $5.5 \%$ (www.who.int/mental_health). Pakistan is the sixth most populous country in the world comprising 176.7 million people with mixed ethnic groups in that around 20 million people suffer from different forms of mental health condition [3].

The prevalence of depression in Pakistani females were $41.9 \%$ as compared to men $29.3 \%$ caused by genetic and environmental factors i.e. social distress, poor status, disappointment in relationships [4]. Antidepressant drug therapy decreases the severity of diseases in that 
fluoxetine and paroxetine are commonly used in Pakistan, China, UAE, UK and USA with recommended dosage $20 \mathrm{mg} / \mathrm{d}$ whereas $30 \mathrm{mg} / \mathrm{d}$ paroxetine used in UK, but unfortunately improper drug metabolism process causes serious complications [5].

Inter-individual variability in drug response is a major problem in clinical practice that has been identified by ineffective drug responses. About $80 \%$ of commercialized drugs are metabolized by polymorphic enzymes family i.e. CYP450 enzymes, which are responsible for phase I metabolism and elimination of numerous endogenous substrates and diverse array of clinical used drugs [6]. The CYP2D6 enzyme is a main member of CYP450 enzyme family, encoded by debrisquine-4-hydroxylase enzyme which is located on chromosome 22 (22q13.1) possess 9 exons with an open reading frame of 1491 base pairs coding for 497 amino acids and 8 introns [7] as shown in figure 1. It is responsible for the biotransformation of psychotropic medications such as antidepressants venlafaxine, fluoxetine, paroxetine and nortriptyline and tricyclics antidepressants $[8,9]$.

Polymorphism in CYP2D6 gene comprises 120 allelic variants of which, CYP2D6*2, $C Y P 2 D 6 * 3, C Y P 2 D 6 * 4, C Y P 2 D 6 * 5, C Y P 2 D 6 * 10, C Y P 2 D 6 * 17$ and $C Y P 2 D 6 * 41$ are most apparent [10]. These allelic variants produce drug metabolizing enzyme with varying degree of catalytic activity i.e. normal, reduced, increased and abolished among individuals in different populations leading to inter-individuals variations and such genotypic variability categorized into four phenotypes viz EM carry both functional alleles, IM carry one functional and one mutant allele, PM carry both defective alleles and UM carry multiple functional copies of functional allele produce increased amount of enzyme to be expressed which enhanced biotransformation and elimination rates of drug [11,12]. 
Around the world, CYP2D6 polymorphic alleles in different population associated with variable drug metabolizing activity such as *3, *4, *5, *6, *7, *8, *11,*12,*13,*14,*15,*16,*18,*19, $* 20, * 21, * 38, * 40, * 42, * 44, * 56$ and $* 62$ have no enzyme activity [11]. CYP2D6*4 allele is predominantly appear in Caucasian. However $* 10, * 17, * 29, * 36$ and $* 41$ give rise to substratedependent low enzymatic activity due to unstable enzyme product [13]. CYP2D6*10 and CYP2D6*36 are frequently found in Asia and East Asia and exhibits reduced substrate affinity. CYP2D6*17 and *29 alleles associated with African and Afrodescedant populations. CYP2D6*41 is found in Middle Eastern populations, [14,15]. Besides that, UMs are more prevalent in the Southern European countries (Spain 7-10\%, Sicily $10 \%$ vs Sweden 1-2\%) [16].

In Pakistan, frequency of $C Y P 2 D 6 * 4$ and $C Y P 2 D 6 * 10$ was determined by Nazir et al in a group of patients (pre-diagnosed with breast cancer) with severity of Tamoxifen induced hot flushes problem [17]. The study provoked us to examine aforementioned allelic variants in depressed patients who develop undesirable response because lack of the CYP2D6 metabolizing pathway after taking antidepressants at standard doses [18].

Currently, there is no data published information about $C Y P 2 D 6$ genetic polymorphisms among depressed patients in Karachi population. The objective of our study was to investigate the frequency of $C Y P 2 D 6$ allelic mutations including $* 1, * 4$ and $* 10$ in Karachi. Of Note, present research approach will generate awareness among clinicians to minimize inadequate antidepressants responses.

\section{Materials and Methods}




\section{Biological sample collection:}

Firstly, the study was approved by International Center for Chemical and Biological Sciences, Ethic Committee (No. 012-BS-2007), University of Karachi to conduct experiments on human subjects. Blood samples were collected from International Center for Chemical and Biological Sciences, University of Karachi, Pakistan. Patient's samples were collected from different hospitals (Civil Psychiatric Hospital and Asghar Psychiatric Hospital) at Karachi. Written consent was taken from participants.

\section{Materials for PCR-Analysis:}

DNA extraction reagents, PCR master kit (Fermentas), primers $(C Y P 2 D 6 * 1 F$ 5'ACAGACCCCTGACCAGTGAC3', CYP2D6*1R 5'TCCAAGGTTGACTCCTGTCC3')

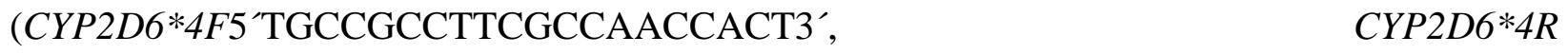

5’TCGCCCTGCAGAGACTCCTC3’) and (CYP2D6*10F5`GTGCTGAGAGTGTCCTGCC3`,CYP2D6*10R5'CACCCACCATCCATGTT TGC 3') (Fermentas). For their restriction analysis the restriction digestion kit (Fermentas) was used, restriction enzymes BstN1 for $C Y P 2 D 6 * 1, C Y P 2 D 6 * 4$ and Hph1 for $C Y P 2 D 6 * 1$ and CYP2D6*10 alleles.

Human genomic DNA was extracted from whole blood $5 \mathrm{~mL}$ by using phenol-chloroform method [19]. PCR amplification was done by using PCR kit. The PCR master mix contained PCR buffer $(10 \mathrm{x}, 5 \mu \mathrm{l})$, dNTPs $(0.2 \mathrm{mM}, 2 \mu \mathrm{l})$, Taq polymerase $(1 \mathrm{U}, 2 \mu \mathrm{l}), \mathrm{H}_{2} \mathrm{O}(30.5 \mu \mathrm{l})$, genomic DNA (250 ng / $5 \mu \mathrm{l})$, primers $(C Y P 2 D 6 * 1 F$ 5'ACAGACCCCTGACCAGTGAC 3', CYP2D6*1R5'TCCAAGGTTGACTCCTGTCC3'), $(C Y P 2 D 6 * 4 F$ 5’TGCCGCCTTCGCCAACCACT3', CYP2D6*4R 5'TCGCCCTGCAGAGACTCCTC3') and (CYP2D6*10F5'GTGCTGAGAGTGTCCTGCC3’,CYP2D6*10R5`CACCCACCATCCATGTT 
TGC 3 $)$ at fixed concentration $(0.35 \mu \mathrm{M}, 1.75 \mu \mathrm{l})$. Appropriate concentrations of $\mathrm{MgCl}_{2}$ for $* 1$ $(1.0 \mathrm{mM}), * 4(1.5 \mathrm{mM}, 3.75 \mu \mathrm{l})$ and $* 10(3 \mathrm{mM}, 7.5 \mu \mathrm{l})$ were added. PCR conditions were optimized and reactions was set (30 cycles for $2.5 \mathrm{~h}$ duration) undergo the steps of DNA denaturation $\left(94^{\circ} \mathrm{C}\right.$ for $\left.1 \mathrm{~min}\right)$, primer annealing $\left(62^{\circ} \mathrm{C}\right.$ for $\left.1 \mathrm{~min}\right) \mathrm{DNA}$ extension $\left(72^{\circ} \mathrm{C}\right.$ for 1 min) and finally, terminal DNA extension $\left(72^{\circ} \mathrm{C}\right.$ for $\left.10 \mathrm{~min}\right)$. The amplimers of $C Y P 2 D 6^{*} 1$, $C Y P 2 D 6 * 4$ and $C Y P 2 D 6 * 10$ were electrophoresed on agarose gel (1\%).

Restriction digestion kit (Fermentas) was used to obtain digested DNA bands. The reaction mixture was prepared which contain PCR products $(10 \mu \mathrm{l})$, nuclease-free water $(18 \mu \mathrm{l})$, reaction buffer $(10 \mathrm{x}, 2 \mu \mathrm{l})$, restriction endonuclease enzymes BstN1 for $C Y P 2 D 6^{*} 1, C Y P 2 D 6^{*} 4$ and Hph1 for $C Y P 2 D 6^{*} 1$, and $C Y P 2 D 6^{*} 10$ alleles then mixed gently and kept for 5 hours at $37^{\circ} \mathrm{C}$ incubation. The digested products were electrophoresed on agarose gel (1\%) then visualized under UV gel documentation system (AlphaInnotech-AlphaImager-3400-Transilluminator Gel Imaging Detection System).

\section{Statistical analysis}

DNA concentration from normal and depressed patients were analyzed by one way ANOVA with $p$ value $<0.05$ or less was considered as significant. Hardy-Weinberg equation was applied for determining gene frequencies $(* 1, * 4$ and $* 10)$ and genotypic frequencies $(* 1 / * 1, * 1 / * 4$, $* 1 / * 10, * 4 / * 10, * 4 / * 4$ and $* 10 / * 10)$ where, $\mathrm{p}(* 1)$ is dominant allele, $\mathrm{q}(* 4)$ and $\mathrm{r}(* 10)$ are

recessive alleles. The observed and expected CYP2D6 genotypic frequencies were analyzed by using non-parametric Chi-square test. 


\section{Results}

\section{Demographic study of participants:}

We employed survey of psychiatric hospital to enroll depressed patients of both gender $(n=45)$ mean ages \pm SD $(36.6 \pm 1.26)$. Normal subjects of both gender $(n=60)$ mean ages \pm SD $(28.7 \pm$ 1.4) were selected. Patients were diagnosed according to the Hamilton Depression Rating scale (HAM-D Key). They were recommended Fluxit, nauxam, zauxit, paroxetine, taxopar with varying dosages $(5-20 \mathrm{mg})$. Females were more affected than males and found to have a history of multiple relapses of depression in medical record file.

\section{Genotyping Results}

Depressed patients and normal subjects were genotyped by PCR and the obtained gene and genotypic frequencies of $C Y P 2 D 6 * 1, * 4$ and $* 10$ alleles were calculated and results showed that mutation is a factor that disrupt the equilibrium of allele frequencies in a population by expressing variants of wild allele. The restriction analysis by BstN1 and Hph1 enzyme produced digested bands of CYP2D6 polymorphic alleles. Percentages of gene frequency were compared between depressed patients and normal subjects.

The Figure- $2 \mathrm{a}$ and $\mathrm{b}$ show the digestion pattern of $C Y P 2 D 6 * 1$ and $C Y P 2 D 6 * 4$ alleles in normal and depressed patients. The BstN1enzyme digested PCR products yielding two fragments (201bp and $108 \mathrm{bp})$ indicate that individuals are homozygous for wild type allele $(* 1 / * 1)$ whereas, three fragments (309bp, 201bp and 108bp) indicates heterozygous individuals $(* 1 / * 4)$ The individuals 
homozygous $(* 4 / * 4)$ for mutant allele showed a single undigested band of $309 \mathrm{bp}$ due to the absence of BstN1 site on both chromosomes.

Figure- 2a and b: Identification of $C Y P 2 D 6^{*} 1$ and $C Y P 2 D 6^{*} 4$ alleles in normal and depressed patients

The Figure- $3 \mathrm{a}$ and $\mathrm{b}$ show the digestion pattern of $C Y P 2 D 6 * 1$ and $C Y P 2 D 6 * 10$ alleles in normal and depressed subjects The Hph1 enzyme digested PCR products were yielding three fragments 183bp, 80bp and 62bp indicated that individuals are homozygous for wild type $(* 1 / * 1)$ allele whereas, four fragments (300bp, 183bp, 80bp and 62bp) indicates heterozygous individuals. The individuals homozygous for $(* 10 / * 10)$ mutant alleles producing two bands $300 \mathrm{bp}$ and $62 \mathrm{bp}$ due to the presence of one Hph1 site on both chromosomes.

Figure- 3a and b: Identification of $C Y P 2 D 6 * 1$ and $* 10$ alleles in normal and depressed patients

\section{CY2D6 Allelic frequency in Karachi population}

The percent frequencies of $C Y P 2 D 6 * 1, * 4$ and $* 10$ alleles in normal and depressed patients were determined using Hardy-Weinberg equilibrium equation for three alleles. It has been noticed $* 1$ allele was predominant wild allele in normal subjects 59\% $(49.6,68.3 \%)$ whereas, $* 4$ allele was highly frequent in depressed $13 \%$ (CI 3.7, 22.3\%) and nearly zero in normal subjects $0.01 \%$ (CI $0,0.1 \%$ ). However, $* 10$ allele was predominant mutant allele in depressed 54\% (CI 44.7, 63.3\%) followed by normal subjects $40 \%$ (CI 30.6, 49.3\%) in Karachi population. Thus frequency of 
wild allele is higher and mutant allele is lower in normal subjects than depressed as presented in Table- 1 and graphically shown in figure- 4 .

Table- 1 CYP2D6 allelic frequency in Karachi population

Figure- 4 Comparison of CYP2D6 alleles $(* 1, * 4$ and $* 10)$ between normal and depressed patients in Karachi population

\section{CYP2D6 genotypic frequencies in Karachi Population}

$* 1 / * 1$ genotype was predominantly found in normal $53 \%$ (CI $46.5,59.4 \%$ ) as compared to depressed 16\% (CI 11.6, 19.4\%) subjects.*1/*4 was appeared 9\% (CI 5.1, 12.9\%) in depressed. $* 1 / * 10$ was predominant in depressed $24 \%$ (CI 20.1, 27.9\%) than normal $10 \%$ (CI 3.57, 16.43\%). 10/*10 was slightly higher in depressed $42 \%$ (CI 38.1, 45.9\%) than normal 35\% (CI

$28.5,41.4 \%)$. None of the normal individual was found with $* 4 / * 4$ genotype although it was (9\% (CI 5.1, 12.9\%) in depressed subjects whereas, $* 4 / * 10$ genotype was absent in all the subjects. Normal individuals with homozygous wild type genotype are comparatively higher than depressed on the contrary depressed patients with either homozygous or heterozygous mutant genotypes for $* 4$ allele are higher than normal which is shown in Table- 2 .

Table- 2 CYP2D6 genotypic frequencies in Karachi population

\section{Allelic frequency in depressed patients of Karachi, UAE and Japanese Population}


The results were also compared with UAE and Japanese population. CYP2D6*1 allele has been noticed (32\%) in Karachi (39.1\%) in UAE and (39.4\%) Japanese, CYP2D6*4 allele is (13\%) in Karachi $(9 \%)$ in UAE and (0\%) in Japanese indicating similar prevalence in Karachi and UAE but no appeared in Japanese patients whereas, $* 10$ is (54\%) in Karachi, (56.7\%) in Japanese but low frequency (3.3\%) in UAE as shown in Figure- 5.

Figure- 5 Comparison of CYP2D6 alleles $(* 1, * 4$ and $* 10)$ between depressed patients of Karachi with UAE and Japanese population

Observed and expected gene frequencies of aforementioned alleles were analyzed by Chi square test for comparing the differences between normal subjects and depressed patients in Karachi population as shown in Table 3.

\section{Discussion}

Tremendous research has been done in the field of pharmacogenomics that emphasized the polymorphic nature of CYP2D6 enzyme contributed high level of inter-individual variation. After administration of drugs patients produce inappropriate response and serious drug induced complications. About $40 \%$ to $70 \%$ depend on type of drug and $15-30 \%$ depends on drug reactions that are developed by $C Y P 2 D 6$ polymorphism [20]. Hence, there is a need to screen out CYP2D6 gene variants in a particular population for analyzing their clinical relevance before unraveling the genotype-phenotype associations. 
So far few research articles published the work that investigated the frequency of CYP2D6 polymorphic alleles among Pakistani population but no one report the information of CYP2D6 polymorphism in depressed patients. Therefore, preliminary study was designed in which three alleles $(C Y P 2 D 6 * 1, C Y P 2 D 6 * 4$ and $C Y P 2 D 6 * 10)$ were assessed.

The results of our study were in agreement with the results of several previously conducted studies. CYP2D6*1 is a wild allele produces functionally active enzyme which metabolizes 160 therapeutic targets, including antidepressants, antipsychotics, anti-arrhythmic, opioid analgesics, anticancer agents [21]. In our study, in normal subjects $(n=60)$, the gene frequencies of CYP2D6*1, CYP2D6*4 and CYP2D6*10 were 59\%, $0.01 \%$ and $40 \%$, respectively. Another research group reported the gene frequencies of $C Y P 2 D 6^{*} 1, C Y P 2 D 6 * 4$ and $C Y P 2 D 6 * 10$ as $74 \%, 1 \%$ and $25 \%,[22]$ among healthy subjects $(\mathrm{n}=155)$ from major ethnic groups in Karachi. The slight differences evident in our studies may be related to small sample size. $C Y P 2 D 6^{*} 1$ was found to be the most frequent in normal subjects of study population as similar as Japanese population and other Asian countries (59\% vs 55\% vs and 50\%) higher than UAE, Koreans and Chinese, $(39 \%, 32 \%$ and $30 \%)$ but lower than Caucasian and Iranian populations (74\% and 83\%) $[23,24,25,26,27,28]$.

However, in depressed patients it was $1.84 \mathrm{x}$ lower than their normal counterparts in Karachi population but closer to depressed patients of UAE and Japanese population (39.1\% and 39.4\%) $[26,29]$. It has been proved experimentally that $C Y P 2 D 6 * 1$ allele in Japanese was closer to Karachiites.

CYP2D $6 * 4$ accounts for $\sim 72 \%$ of all null alleles worldwide and reported to be absent in Asian population. Japanese, Chinese, East Asian, UAE, Iranian and Hong Kong populations (0\%, 0\%, $0.3-0.5 \%, 2 \%, 2 \%$ and $4.6 \%)[26,28,30]$. However, due to the presence of single heterozygous 
individual $(* 1 / * 4)$ in normal subjects very low or negligible allelic frequency $(0.01 \%)$ was found in Karachi population. On the contrary, the frequency of $C Y P 2 D 6 * 4$ was higher in Caucasians $(20 \%)[23,29]$.

The same $C Y P 2 D 6 * 4$ allele in depressed patients of Karachi population was found to be (13\%) closer to another research group who reported gene frequency in northern Pakistani population including Meo (13.64\%), Punjabi (11.96\%) and Pathan (10.42\%). Low frequency $(<4 \%)$ of $* 4$ polymorphism was observed in Kalash and Makrani groups, whereas an intermediate frequency (5-9\%) in all the other ethnic groups [31]. In depressed subjects from UAE population $* 4$ is (9\%) slightly lower than local population but higher than Japanese population $(0 \%)$. [24, 25, 28] It may be due to greater number of heterozygous individuals relocate between these regions that may raise the frequency of $C Y P 2 D 6 * 4$ allele in our population.

Individuals carrying CYP2D6*4 mutant allele are more susceptible to develop side-effects with normal doses $(20 \mathrm{mg} / \mathrm{d})$ of antidepressants fluoxetine and paroxetine as they are poor metabolizer $(* 4 / * 4)$ genotype and hence showed high drug concentrations in their plasma. Therefore, low doses about half the therapeutic doses should be prescribed which will be served for two purposes i.e. minimize the side effects of the drug and cost burden on the patient will also be reduced.

CYP2D6*10 is the most frequent mutant allele in Asian population (50\%). It was found to be (40\%) in Karachi closer to Korean, Japanese and East Asian (46.2\% and 39\%, 37.5-52.5\%) but very low in Caucasian populations (1.4\%) in accordance with other Asian population. However, in depressed patients of Karachi Population it was found to be (54\%) similar in Japanese (56.7\%) but significantly higher than $\operatorname{UAE}(3.3 \%)[26,29,14]$. According to the study of Japanese depressed patients $C Y P 2 D 6 * 10$ allele showed significant impact on the plasma paroxetine 
concentrations in Asians. Therefore, it has been proposed for Asian patients with CYP2D6*10 allele paroxetine drug monitoring is necessary for preventing overdose. The genotyping screening parameters is necessary to optimize dose in each patient [29].

Additionally, in present study difference of CYP2D6 variants expression was found between patients and normal subjects irrespective of ethnic diversity. Due to study limitation, data was not analyzed for protein translation of CYP2D6 mutant enzymes in order to confirm genotypic expression into phenotypic drug metabolizing enzyme formation.

The similarities and dissimilarities in the occurrence of various alleles strongly suggests that population based studies should be taken into account before marketing drugs in different countries. Most importantly, same drug dosages cannot be recommended worldwide emphasizing individualized treatment for efficacious and safe therapeutic response.

In Pakistan, multiple research organizations are needed to be established for designing and sharing CYP2D6 gene testing techniques in different provinces. This perspective might be prolonged to uncover related gene markers that bio-transformed antipsychotic medication to avoid sufferings of depression [32]. However, PharmVar database was launched in 2018, which is actually gene based catalogue that updated allelic variation of genes impacting on drug metabolism. Clinical Pharmacogenetics Implementation Consortium (CPIC) develops guidelines that captured information of allelic frequencies from different population across the world and doing translation of genetic laboratory test to confirm genetic variants and further specific drugs recommendation $[33,34]$. Thereby, we need to initiate extensive CYP2D6 genetic analysis by utilizing sequence-based approaches to detect maximum number of allelic variants having abolished activity of drug metabolism and update the information. Furthermore, 
pharmacogenomics (PGx) guidelines need to be implemented for predicting phenotypes before suggest specific drug dosage.

\section{Conclusion}

In view of the present findings, $C Y P 2 D 6^{*} 4$ and $* 10(13 \%$ and $54 \%)$ are frequent variants of CYP2D6 gene, associated with inter-individual variability that induce improper drug metabolism among patients with a family history of depression and using co-medication as a consequence undesirable side effects may develop that impede patient's therapeutic response. To avoid these and for safer therapeutic responses gene screening is demanded. Although, there are some limitations in our study and paucity of available data, extensive research is demanded for characterizing CYP2D6 gene profile and monitoring patient's drug metabolic activity. In future, study with large sample need to be conducted and expand to national level.

\section{Authorship}

Dr. Ahsana Dar participated in study design and supervision, Tamkeen Fatima participated in recruitment of patients, performance of the research, data analysis and writing of the paper, Farah. Zeb participated in the recruitment of patients.

\section{Funding}

This research did not receive any specific grant from funding agencies in the public, commercial, or not-for-profit sectors. 


\section{Declaration of Competing Interest}

The authors declare no potential conflict of interest with respect to the authorship and publication of this article.

\section{Acknowledgments}

The authors thank for recruited subjects, clinicians and all contributors in this study.

\section{References}

[1] Whiteford HA, Degenhardt L, Rehm J, et al. Global burden of disease attributable to mental and substance use disorders: findings from the Global Burden of Disease Study 2010. Lancet., 382 (2013), pp. 1575-86.

[2] Murray CJ, Lopez AD. Global mortality, disability, and the contribution of risk factors: Global Burden of Disease Study. Lancet., 349 (1997), pp. 1436-42. PMID: 9164317.

[3] World Health Organization: WHO-AIMS report on mental health system for Pakistan. Geneva: World Health Organization.: https://www.who.int/mental_health/pakistan. Accessed: January 26, (2019). 
[4] Aysha Zahidie and Tanzil Jamali. An Overview of the Predictors of Depression Among Adult Pakistani Women. J. Coll. of Phys. and Surg. Pak., 23 (2013), pp. 574-58.

[5] Bertilsson M, Eichelbaum B. Clinical relevance with focus on psychotropic drugs. B. J. Clin Pharmacol., 53 (2002), (53), pp. 111-122.

[6] Eichelbaum M, Baur MP, Dengler HJ, Osikowska-Evers BO, Tieves G, Zekorn C, Rittner C. Chromosomal assignment of human cytochrome P-450 (debrisoquine/sparteine type) to chromosome 22. Br J Clin Pharmacol., 23 (1987), pp. 455-8.

[7] Kimura, S.; Umeno, M.; Skoda, R.C.; Meyer, U.A.; Gonzalez, F.J. The human debrisoquine 4-hydroxylase (CYP2D) locus: Sequence and identification of the polymorphic CYP2D6 gene, a related gene, and a pseudogene. Am. J. Hum. Genet., 45 (1989), pp. 889-904.

[8] Zanger UM, Schwab M. Cytochrome P450 enzymes in drug metabolism: regulation of gene expression, enzyme activities, and impact of genetic variation. Pharmacol Therapy., 138 (2013), pp. 103-141. doi:10.1016/j.pharmthera.2012.12.007

[9] Kirchheiner, J., Nickchen, K., Bauer, M. et al. Pharmacogenetics of antidepressants and antipsychotics: the contribution of allelic variations to the phenotype of drug response. Mol Psychiatry., 9 (2004), pp. 442-473.

[10] Ingelman-Sundberg M. Human drug metabolising cytochrome P450 enzymes: properties and polymorphisms. Naunyn Schmiedebergs Arch. Pharmacol., 369 (2004), pp. 89-104. 
[11] Zhou SF. Polymorphism of human cytochrome P450 2D6 and its clinical significance: Part I. Clin. Pharmacok., 48 (2009), pp. 689-723.

[12] Ingelman-Sundberg, M. Genetic polymorphisms of cytochrome P450 2 D6 (CYP2D6): clinical consequences, evolutionary aspects and functional diversity. Pharmaco., 5 (2005), pp. 6-13.

[13] Bradford LD. CYP2D6 allele frequency in European Caucasians, Asians, Africans and their descendants. Pharmacogen., 3 (2002), pp. 229-243.

[14] Kiyotani K, Shimizu M, Kumai T, Kamataki T, Kobayashi S, Yamazaki H. Limited effects of frequent CYP2D6*36-*10 tandem duplication allele on in vivo dextromethorphan metabolism in a Japanese population. Eur J Clin Pharmacol., 66(10) (2010), pp.1065-1068.

[15] LLerena A, LLerena A, Naranjo ME, et al. Interethnic variability of CYP2D6 alleles and of predicted and measured metabolic phenotypes across world populations. Expert Opinion on Drug. Metabol. Toxicol., 10 (2014), pp.1569-1583.

[16] Fuselli S, Dupanloup I, Frigato E, Cruciani F, Scozzari R, Moral P, Sistonen J, Sajantila A, Barbujani G. Molecular diversity at the CYP2D6 locus in the Mediterranean region. Eur J Hum Genet. Nov; 12(11): (2004), pp. 916-24.

[17] Nazir N, Waheed A, Farhat K, Ismail M, Mansoor Q. Frequency of CYP2D6*10 genotypes in Pakistani breast cancer patients taking adjuvant tamoxifen. $\mathrm{J}$ Pak Med Association 66(12) (2016), pp. 1554-1558. 
[18] Kato D, Kawanishi C, Kishida I, et al. CYP2D6 gene deletion allele in patients with neuroleptic malignant syndrome: preliminary report. Psychiatry Clin Neurosci., 59 (2005), pp. 504-507.

[19] M. Ausubel, R. Brent, R.E. Kingston, D.D. Moore, J.G. Seidman, J.A. Smith, and K. Struhl. Volumes 1 and 2. John Wiley \& Sons, Inc., Media, PA, Current protocols in molecular biology. (1988).

[20] Eichelbaum M, Ingelman-Sundberg M, Evans WE. Pharmacogenomics and individualized drug therapy. Annu Rev Med., 57 (2006), pp. 119-37.

[21] Ingelman-Sundberg M, Sim SC, Gomez A, Rodriguez-Antona C. Influence of cytochrome $\mathbf{P 4 5 0}$ polymorphisms on drug therapies: pharmacogenetic, pharmacoepigenetic and clinical aspects. Pharmacol. Ther., 116 (2007), pp. 496-526.

[22] Afsar, N.A., Bruckmueller, H., Werk, A.N. et al. Implications of genetic variation of common Drug Metabolizing Enzymes and ABC Transporters among the Pakistani Population. Sci Rep., (9) (2019), pp. 7323.

[23] Byeon JY, Kim YH, Lee CM, Kim SH, Chae WK, Jung EH, Choi CI, Jang CG, Lee SY, Bae JW, Lee YJ. CYP2D6 allele frequencies in Korean population, comparison with East Asian, Caucasian and African populations, and the comparison of metabolic activity of CYP2D6 genotypes. Arch. Pharm. Res., (2018).

[24] Ismail R, Tah LK et al. Genetic polymorphism of CYP2D6 in Chinese subjects in Malaysia. Clin. J.Pharmacol.Therapeu., 28 (2003), pp. 279-284 
[25] Kubota T, Yamaura Y, Ohkawa N, Hara H, Chiba K. Frequencies of CYP2D6 mutant alleles in a normal Japanese population and metabolic activity of dextromethorphan 0 demethylation in different CYP2D6 genotypes. B. J. Clin. Pharmacol., 50 (2000), pp. 31-34.

[26] Qumsieh RY, Ali BR, Abdulrazzaq YM, Osman O, Akawi NA, Bastaki SM. Identification of new alleles and the determination of alleles and genotypes frequencies at the CYP2D6 gene in Emiratis. PLoS. One., 6 (2011); pp. 28943.

[27] Lee etal . Discovery of Novel Functional Variants and Extensive Evaluation of CYP2D6 Genetic Polymorphisms in Koreans. Drug. Metabol. Dispos., 37 (2009), pp. 14641470

[28] Kouhi H, Hamzeiy H, Barar J, Asadi M, Omidi Y. Frequency of five important CYP2D6 alleles within an Iranian population (Eastern Azerbaijan). Genet Test Mol Biomarkers.,13(5) (2009), pp. 665-70. PMID: 19715474

[29] Saruwatari J, Nakashima H, Tsuchimine S, Nishimura M, Ogusu N, Yasui-Furukori N. Possible impact of the CYP2D6*10 polymorphism on the nonlinear pharmacokinetic parameter estimates of paroxetine in Japanese patients with major depressive disorders. Pharmgenomics. Pers. Med.,7 (2014), pp. 121-127.

[30] Barcelo MG, Chow LY et al. Genetic Analysis of the CYP2D6 Locus in a Hong Kong Chinese Population. Clin. Chem., 46 (2000), pp. 18-23

[31] Ullah A, Riaz S, Siddiqi S, Mazhar K, Mansoor A. Report - CYP2D6*4 null allele frequency in sixteen Pakistani ethnic groups. Pak J Pharm Sci., 33(2) (2020), pp. 739-743. 
[32] Dunnenberger HM, Crews KR, Hoffman JM, Caudle KE, Broeckel U, Howard SC, et al. Preemptive clinical pharmacogenetics implementation: current programs in five US medical centers. Annu Rev PharmacolToxicol., 55 (2015)8, pp. 9-106.

[33] Hicks JK, Sangkuhl K, Swen JJ, et al. Clinical pharmacogenetics implementation consortium guideline (CPIC) for CYP2D6 and CYP2C19 genotypes and dosing of tricyclic antidepressants: 2016 update. Clin Pharmacol Ther., 102 (2017), pp. 37-44.

[34] Crews KR, Gaedigk A, Dunnenberger HM, Leeder JS, Klein TE, et al. Clinical Pharmacogenetics Implementation Consortium guidelines for cytochrome P450 2 D6 genotype and codeine therapy. Clin Pharmacol Ther., 95 (2014), pp. 376-382. 